\title{
Mechanical Strength and Wear of Dental Glass-Ionomer and Resin Composites Affected by Porosity and Chemical Composition
}

\author{
Daniela S. Rodrigues ${ }^{1} \cdot$ Mihaela Buciumeanu $^{2}$ - Antonio E. Martinelli ${ }^{3}$. \\ Rubens M. Nascimento ${ }^{3}$ Bruno Henriques ${ }^{4,5}$ - Filipe S. Silva ${ }^{4}$ Júlio C. M. Souza ${ }^{4,5}$
}

Received: 16 July 2015/Revised: 25 July 2015/Accepted: 1 August 2015/Published online: 13 August 2015

(c) Springer International Publishing AG 2015

\begin{abstract}
The main aim of this study was to evaluate the influence of porosity, microstructure, and chemical composition on the wear and compressive strength of dental glass-ionomer or resin composite. Cylindrical samples $(6 \times 4 \mathrm{~mm})$ were prepared from a nano-hybrid resin composite (Grandio ${ }^{\circledR} \mathrm{SO} / \mathrm{RC}, \mathrm{VOCO}$ ), a resin-modified glass ionomer (Vitremer ${ }^{\mathrm{TM}} / \mathrm{VI}, 3 \mathrm{M}-\mathrm{ESPE}$ ) and a conventional glass ionomer (Ionofil ${ }^{\circledR}$ Molar/CO, VOCO). Porosity and topography of the materials were evaluated by optical and scanning electron microscopy (SEM). Roughness was evaluated by $R_{\mathrm{a}}$ and $R_{\mathrm{t}}$ parameters at $0.1 \mathrm{~mm} / \mathrm{s}$ under cutoff of $0.8 \mathrm{~mm}$. Then, compressive tests were performed at $1 \mathrm{~mm} / \mathrm{min}$. Wear tests were carried out at $20 \mathrm{~N}, 2.5 \mathrm{~mm}$ of displacement, at $1 \mathrm{~Hz}$ for $90 \mathrm{~min}$ in artificial saliva solution. The results were statistically analyzed with a one-way ANOVA and Tukey's test $(p<0.05)$. Resin composite revealed a significantly lower porosity $(1.21 \pm 0.20 \%)$ than glass-ionomer restoratives (5.69-7.54\%) as well as
\end{abstract}

Júlio C. M. Souza

julio.c.m.souza@ufsc.br; jsouza@dem.uminho.pt

1 School of Dentistry, Universidade Fernando Pessoa (UFP), 4200-150 Porto, Portugal

2 "Dunarea de Jos" University of Galati, Domneasca 47, 800008 Galati, Romania

3 Department of Materials Engineering, Universidade Federal do Rio Grande do Norte (UFRN), Natal, RN 5900-000, Brazil

4 Centre Microelectromechanical Systems (CMEMS), Department of Mechanical Engineering (DEM), Universidade do Minho, Campus Azurém, 4800-058 Guimarães, Portugal

5 Post-Graduation Program in Dentistry (PPGO), School. of Dentistry (ODT), Universidade Federal de Santa Catarina (UFSC), Florianópolis, SC 88040-900, Brazil lower values of $R_{\mathrm{a}}$ and $R_{\mathrm{t}}$ roughness $(p<0.05)$. Also, resin composite showed significantly higher values of mechanical strength $(334 \pm 15.9 \mathrm{MPa})$ compared to conventional $(78.78 \pm 13.30 \mathrm{MPa})$ or modified glass ionomer $(169.50 \pm$ $20.98 \mathrm{MPa})(p<0.05)$. For maximal depth of wear, resin composite also showed significantly lower values than glass ionomer $(p<0.05)$. Homogeneous wear morphology was noticed by SEM analyses on glass ionomers in opposition to resin composite. Glass ionomers showed a poor mechanical behavior associated to a high porosity and wear rate when compared to resin composite.

Keywords Glass-ionomer - Resin composite · Compressive strength $\cdot$ Porosity $\cdot$ Microstructure $\cdot$ Wear

\section{Introduction}

One of the most common procedures in dental practice is the replacement of the lost or damaged dental hard tissues. Glass ionomer, resin-modified glass ionomers, and resin composites are nowadays the most used materials in dentistry for direct dental restorations [1-4]. Currently, resin composites are the materials of first choice for anterior and posterior dental restorations due to their excellent optical properties associated with adequate mechanical and biological properties. Resin composites are composed of a mixture between an organic matrix and inorganic fillers [2, 3]. Their physical and mechanical properties strongly depend on some factors, such as filler content; integrity of the organic-to-fillers adhesion; porosity percentage of the cured material, and on the oral environment [1, 3, 4]. Regarding strength, current materials are nearly as mechanically strength as dental amalgams and porcelain [3]. The wear is also considered to be an issue for 
commercial resin composites depending on the refinement of the size and composition of the fillers that can decrease the extent of abrasive wear. In fact, the wear and strength of those resin composites deserve attention when placed over an extensive area, as in several teeth or replacement of tooth cusps [2-4].

The glass-ionomer materials are characterized by their acid-base setting reaction between a fluoroaluminosilicate glass powder and a solution of polyalkenoic acids [1, 4]. Such materials exhibit adhesive properties to tooth structures resulting in marginal effective sealing, in addition to their ability to release fluoride ions to the surrounding oral tissues. That helps in the prevention and control of tooth decay. However, glass-ionomer restoratives exhibit poor physical-mechanical properties as compared to resin composites, including low mechanical strength and wear resistance [5,6]. That is the resultant from high percentage of porosity and microstructure of the material [7, 8]. Consequently, the low wear resistance causes changes in the restorative anatomy and increase of the surface roughness [4, 6]. Light-cured resins have been added in the resin-modified glass ionomers as intent to overcome the associated problems with early moisture sensitivity and also on their low mechanical strength $[9,10]$.

The purpose of this in vitro study was to evaluate the influence of porosity, chemical composition, and microstructure on wear mechanisms and compressive mechanical strength of dental resin composites or glass-ionomer restorative materials. The null hypothesis of this study was that there is no influence of chemical composition and porosity on the wear rate or compressive mechanical strength of both materials.

\section{Materials and Methods}

\subsection{Synthesis of the Specimens}

One nano-hybrid resin composite and two different glass ionomers were assessed in this study as shown in Table 1 .

Cylindrical specimens composed of resin composite or glass ionomer were prepared in a Teflon split mold with dimensions of $4 \mathrm{~mm}$ diameter and $6 \mathrm{~mm}$ depth. Specimens were synthesized by a single operator according to the manufacturer's instructions. Except for self-cured conventional glass ionomer, all specimens were light-cured using Coltolux 75 (Coltène/Whaledent, Altstätten, Switzerland) curing device at $1000 \mathrm{~mW} / \mathrm{cm}^{2}$ for $40 \mathrm{~s}$ on top and bottom surfaces. Then the specimens were taken out from the Teflon mold and additionally light-cured for $40 \mathrm{~s}$ on each cylindrical side surface.

After polymerization, glass ionomer and resin-modified glass-ionomer samples were stored in $100 \%$ relative humidity. Fifteen specimens were synthesized on each group of material. Ten specimens were embedded in acrylic resin and then sectioned for the following analyses: optical microscopy, scanning electron microscopy (SEM), wear tests, and roughness analyses. The cross-sectioning was carried out by wet grinding on $\mathrm{SiC}$ papers (Mecapol P 251, PRESI, France) from 380 down to 1200 mesh followed by polishing with slurry of $1 \mu \mathrm{m}$ diamond particles. After that, those specimens were ultrasonically cleaned (Axtor CD-4820, Lovango, Spain) in distilled water for $15 \mathrm{~min}$. The other remaining samples were used for the axial compressive tests.

\subsection{Microstructural Analyses}

The porosity analyses were performed using an optical microscope (Leica DM 2500 M, Leica Microsystems, Germany) connected to a computer to image processing, using Leica Application Suite software (Leica Microsystems, Germany). A number of six micrographs were obtained at $\times 50$ magnification, for each specimen $(n=60)$ involving the entire specimen area. The software Adobe Photoshop (Adobe Systems Software, Ireland) was used to analyze black and white images, with the black representing the pores and the white the bulk material. Image $J$ software (National Institutes of Health, USA) was used to quantify the porosity percentage.

Surfaces of the materials were sputter-coated with $\mathrm{Ag}-$ $\mathrm{Pd}$ and then inspected using field emission gun-scanning electron microscope (FEG-SEM, FEI Quanta 400, USA) equipped with energy-dispersive X-ray spectroscopy (EDAX Pegasus X4 M).

\subsection{Roughness Measurement}

The surface roughness was measured using an optical profilometer (Mahr Perthen, Germany) at a measurement length of $2 \mathrm{~mm}$, cut-off value of $0.8 \mathrm{~mm}$ at $0.1 \mathrm{~mm} / \mathrm{s}$. Three measurements were carried out on different surface areas for each specimen $(n=15)$. Two roughness parameters were evaluated: average roughness, $R_{\mathrm{a}}$, (average of the values obtained between peaks and valleys, distance from the profile mean line) and the maximum distance between peaks and valleys of the profile, $R_{\mathrm{t}}$.

\subsection{Compressive Strength Tests}

The compressive strength tests were performed at a room temperature of $23{ }^{\circ} \mathrm{C}$ using a universal testing machine (Instron 8874, MA, USA) at a crosshead speed of $1 \mathrm{~mm} /$ min. Before mechanical test, the specimens were immersed in distilled water for $24 \mathrm{~h}$. Specimens $(n=5)$ were then positioned vertically on the testing machine base and 
Table 1 Materials used in the study. The chemical composition was obtained from manufacturers and previous studies [1-5, 9, 10, 21, 23]

\begin{tabular}{|c|c|c|c|}
\hline $\begin{array}{l}\text { Materials } \\
\text { (groups) }\end{array}$ & Manufacturers & Matrix & Fillers $(w / w)$ \\
\hline $\begin{array}{l}\text { Nano-hybrid } \\
\text { resin } \\
\text { composite } \\
\text { (RC) }\end{array}$ & $\begin{array}{l}\text { Grandio }{ }^{\circledR} \mathrm{SO}, \\
\text { VOCO, } \\
\text { Germany }\end{array}$ & Bis-GMA, Bis-EMA, TEGDMA & $\begin{array}{l}89 \% \text { functionalized silicon dioxide nano- } \\
\text { particles }(20-40 \mathrm{~nm}) \text { and zirconia glass fillers } \\
(1 \mu \mathrm{m})\end{array}$ \\
\hline $\begin{array}{l}\text { Resin- } \\
\text { modified } \\
\text { glass } \\
\text { ionomer } \\
(\mathrm{VI})\end{array}$ & $\begin{array}{l}\text { Vitremer }^{\mathrm{TM}} \\
3 \mathrm{M} \text {-ESPE, } \\
\text { USA }\end{array}$ & $\begin{array}{l}\text { Aqueous solution of a polycarboxylic acid modified with } \\
\text { dimethacrylate, HEMA, photoinitiators }\end{array}$ & $\begin{array}{l}\text { Fluoroaluminosilicate glass, microencapsulated } \\
\text { potassium persulfate, ascorbic acid, } \\
\text { and pigments }(6.25 \mu \mathrm{m})\end{array}$ \\
\hline $\begin{array}{l}\text { Glass- } \\
\text { ionomer } \\
(\mathrm{CO})\end{array}$ & $\begin{array}{l}\text { Ionofil }{ }^{\circledR} \text { Molar, } \\
\text { VOCO, } \\
\text { Germany }\end{array}$ & Aqueous solution of a polycarboxylic, tartaric acid & $\begin{array}{l}\text { Fluoroaluminosilicate glass and pigments } \\
\qquad(5 \mu \mathrm{m})\end{array}$ \\
\hline
\end{tabular}

subjected to axial compressive loading up to fracture. The mean values of compressive strength were obtained. The tests were recorded using the Trapezium (Shimadzu Corporation, Japan) software and the compressive strength values were calculated from the equation $F / \pi r^{2}$, where $F$ is the maximum load at fracture and $r$ the radius of the cylindrical specimen [8].

\subsection{Wear Tests}

Before wear testing, the specimens were stored in distilled water for $24 \mathrm{~h}$. The specimens $(n=5)$ were placed in an electrochemical cell and immersed in a Fusayama artificial saliva solution (see Table 2) at $37{ }^{\circ} \mathrm{C}$. Reciprocating wear sliding tests were performed against an alumina ball (Goodfellow, UK) of $10 \mathrm{~mm}$ diameter at a normal load of $20 \mathrm{~N}, 1 \mathrm{~Hz}$, and a linear displacement amplitude of $2.5 \mathrm{~mm}$ for $90 \mathrm{~min}$ using a tribometer (CETR UMT2 Multi-specimen test system, Bruker, USA). The tribometer was coupled to the UMT test viewer software to monitor the tangential force $\left(F_{t}\right)$ from which the coefficient of friction (COF) was calculated.

The maximal depth of wear was measured using the optical profilometer (Mahr Perthen, Germany).

Table 2 Composition of the Fusayama artificial saliva solution used in this work

\subsection{Statistical Analysis}

The results were statistically analyzed via one-way analysis of variance (ANOVA), using a significance level of $p<0.05$. Tukey's test for multiple comparisons was used to determinate significant differences among the materials in each group.

\section{Results}

\subsection{Microstructural Analyses}

The images obtained by optical microscopy of the materials used in this study are shown in Fig. 1. It can be clearly noticed that the nano-hybrid resin composite revealed a lower number of pores (black circular points) (Fig. $1 \mathrm{~A}$ ) in comparison to glass-ionomer materials (Fig. 1c, e). Cracks were noticed surrounding the fillers and also linked the pores in glass ionomers(Fig. 1c, e).

FEG-SEM micrographs obtained by backscattered electrons of the materials surface are also shown in Fig. 1b, $\mathrm{d}$ and $\mathrm{f}$ ). Resin composite revealed smaller filler size (Fig. 1b) than those in resin-modified (Fig. 1d) or conventional ionomer (Fig. 1f).

The mean values and standard deviations of the porosity percentage measurements (see Fig. 2) revealed statistically significant difference between the material groups $(p<0.05)$. Glass ionomer showed the highest porosity percentage $(7.54 \pm 0.27 \%)$, followed by resin-modified glass ionomer $(5.69 \pm 0.27 \%)$. Nano-hybrid resin composites revealed a low porosity percentage $(1.21 \pm 0.2 \%)$.

\subsection{Roughness Measurements}

The results of the roughness measurements, $R_{\mathrm{a}}$ and $R_{\mathrm{t}}$, are shown in Fig. 3. Regarding $R_{\mathrm{a}}$ roughness, measurements 

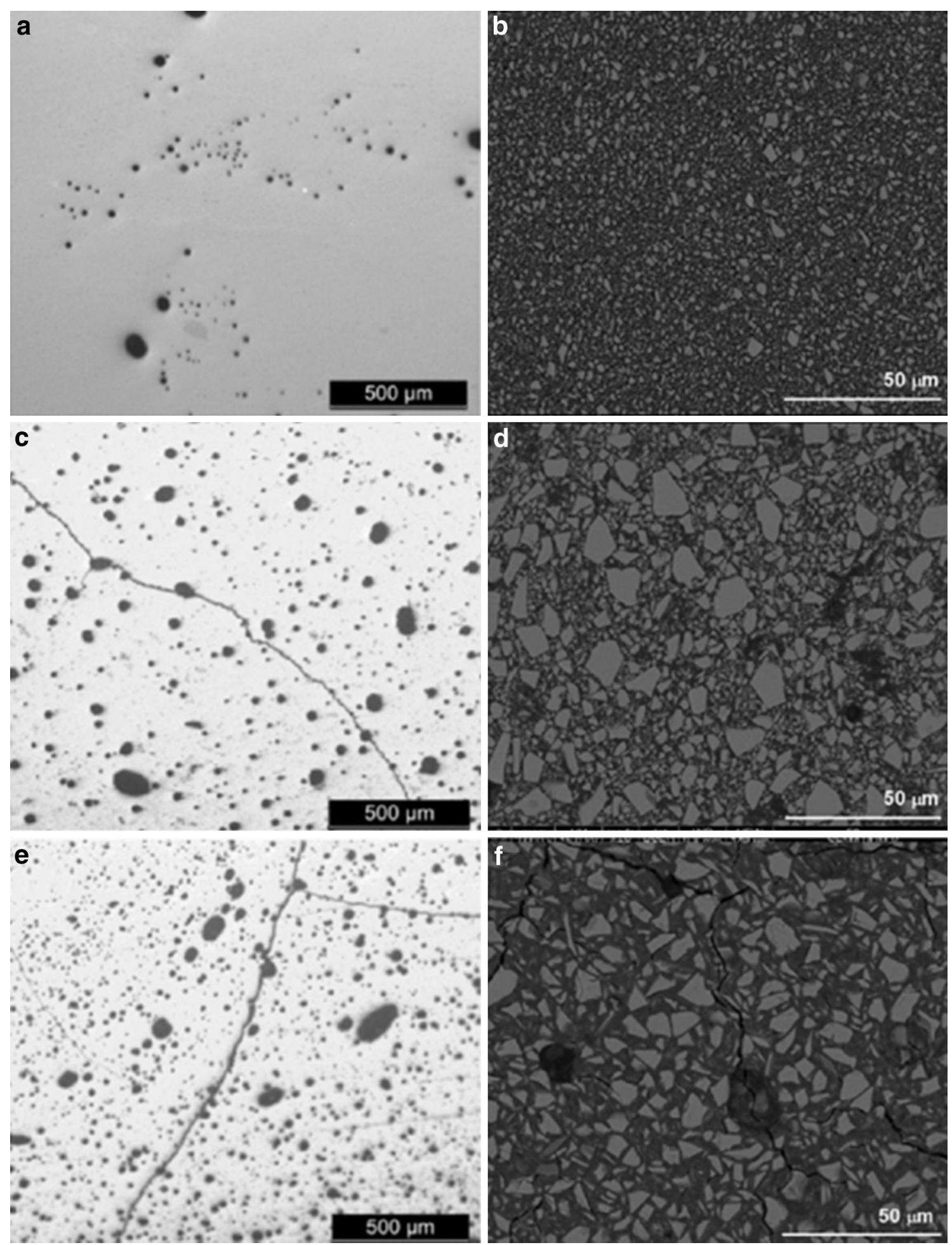

Fig. 1 Optical microscopy images of a resin composite, $\mathbf{c}$ resinmodified glass ionomer and e conventional glass ionomer (pores appear as dark circular points). FEG-SEM images of $\mathbf{b}$ resin

composite, $\mathbf{d}$ resin-modified glass ionomer and $\mathbf{f}$ conventional glass ionomer (images obtained at $\times 2000$ magnification by backscattered electron mode at $15 \mathrm{kV}$ )

(see Fig. 3a), conventional glass ionomer showed a statistically significant rougher surface $(0.29 \pm 0.16 \mu \mathrm{m})$ than that on resin composite $(0.04 \pm 0.01 \mu \mathrm{m}) \quad(p<0.05)$.

Resin-modified glass ionomer revealed an average roughness of $0.21 \pm 0.09 \mu \mathrm{m}$. Considering $R_{\mathrm{t}}$ measurements (see Fig. 3b), conventional and resin-modified glass 


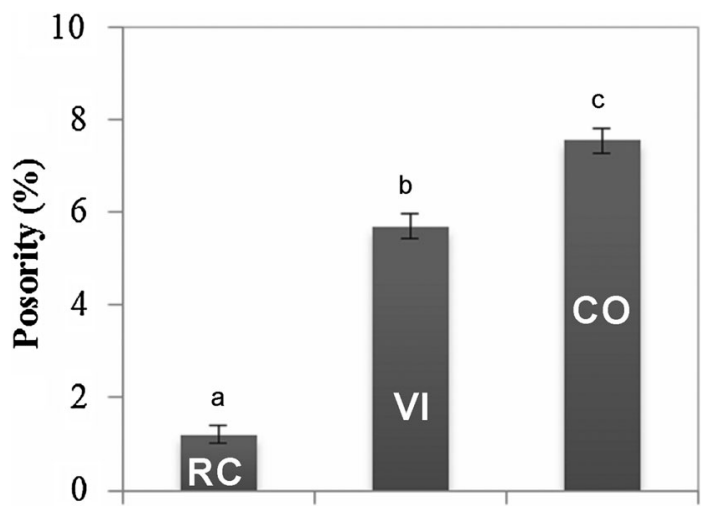

Fig. 2 Mean porosity percentage recorded on resin composite resin $(R C)$, resin-modified glass ionomer $(V I)$ and conventional glassionomer $(C O)$. ${ }^{\text {a } V a l u e s ~ w i t h ~ s a m e ~ l e t t e r ~ r e v e a l e d ~ n o ~ s i g n i f i c a n t ~}$ differences $(p<0.05)$

ionomer showed higher roughness values $(8.29 \pm 2.87 \mu \mathrm{m}$ and $7.12 \pm 1.78 \mu \mathrm{m}$ ) than that recorded on resin composite $(0.38 \pm 0.17 \mu \mathrm{m})(p<0,05)$. There were no statistically significant differences detected between the $\mathrm{CO}$ and VI groups $(p>0.05)$.

\subsection{Compressive Strength}

The mean values of compressive strength (see Fig. 4) were significantly different between the material groups $(p<0.05)$. The highest values of compressive strength were recorded for resin composite $(334.23 \pm 15.92 \mathrm{MPa})$ when compared to resin-modified glass ionomer $(169.5 \pm 20.98 \mathrm{MPa})$ and conventional glass ionomer $(78.78 \pm 13.3 \mathrm{MPa})$.

\subsection{Wear Analyses}

FEG-SEM micrographs obtained by secondary or backscattered electrons of the materials are shown in Fig. 5. Wear scars of the materialś worn surface are noticed

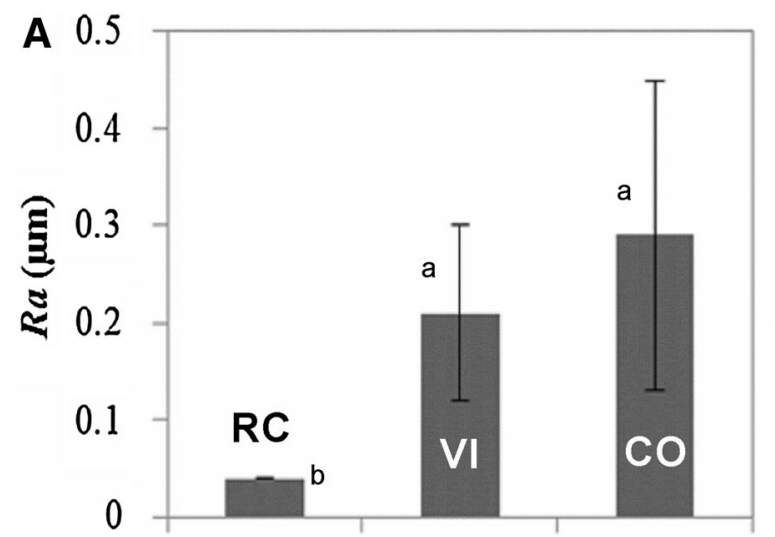

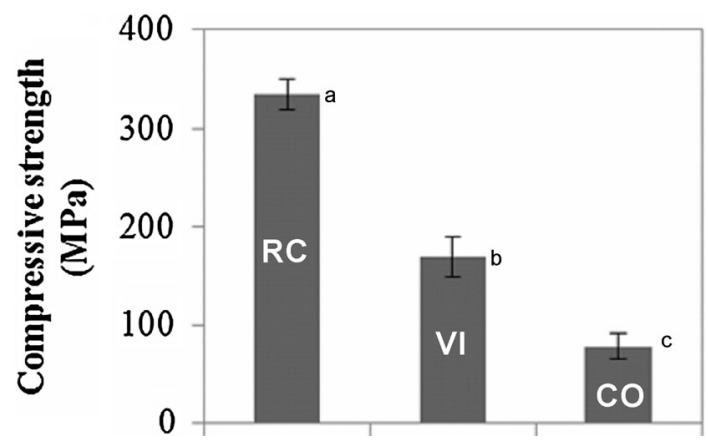

Fig. 4 Mean values of compressive strength recorded on resin composite resin $(R C)$, resin-modified glass ionomer $(V I)$, and conventional glass ionomer. ${ }^{a}$ Values with same letter revealed no significant differences $(p<0.05)$

in Figs. 5a, b, and e. The largest damaged area was recorded on conventional glass ionomer $\left(2.403 \mathrm{~mm}^{2}\right)$ compared to resin-modified glass ionomer $\left(1.793 \mathrm{~mm}^{2}\right)$ and resin composite $\left(1.452 \mathrm{~mm}^{2}\right)$. Worn surfaces of the resin composite and glass-ionomer materials revealed different morphological aspects of wear (Fig. 5b, d, and f). Simultaneous ejection of a mixed matrix-filler layer was noticed on resin composite. However, cracks were noticed at matrix-filler interfaces on glass ionomers indicating an ejection of inorganic fillers from that material.

Those materials showed different evolution of $\mathrm{COF}$ against alumina ball at $20 \mathrm{~N}$ in artificial saliva as noticed in Fig. 6. The COF measured on resin composite was about 0.55, while the maximum depth of wear was at $17 \pm 1.1 \mu \mathrm{m}$. Conventional glass ionomer $(\mathrm{CO})$ revealed a lower $\mathrm{COF}$ value at about 0.51 although the maximum depth value of wear was the highest $(49.54 \pm 7.4 \mu \mathrm{m})$ recorded on the damaged surfaces. On resin-modified glass ionomer (VI), the COF recorded was significantly lower $(p<0.05)$, down to 0.45 , while the maximum depth of wear was at $28.31 \pm 3.1 \mu \mathrm{m}$. The mean values of wear depth (see Fig. 6) were significantly different between the material groups $(p<0.05)$.

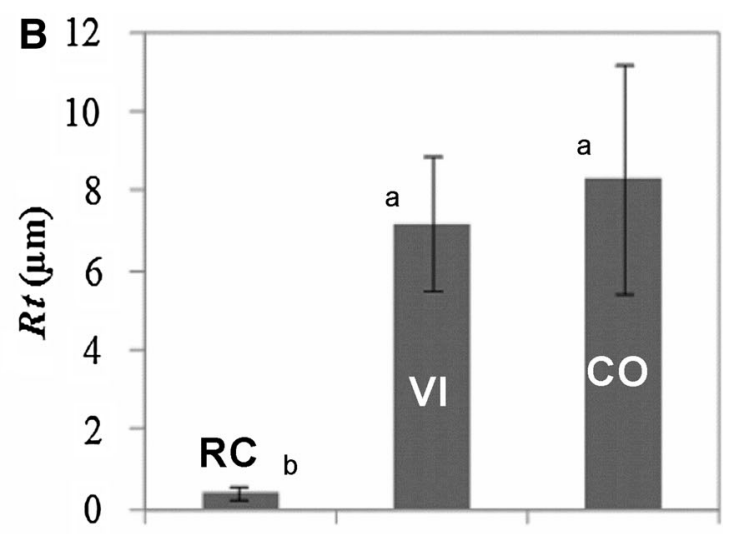

Fig. 3 Mean $R_{\mathrm{a}}$ and $R_{\mathrm{t}}$ roughness values recorded on resin composites $(R C)$, resin-modified glass ionomer $(V I)$ and conventional glass ionomer $(C O) .{ }^{a}$ Values with same letter revealed no significant differences $(p<0.05)$ 

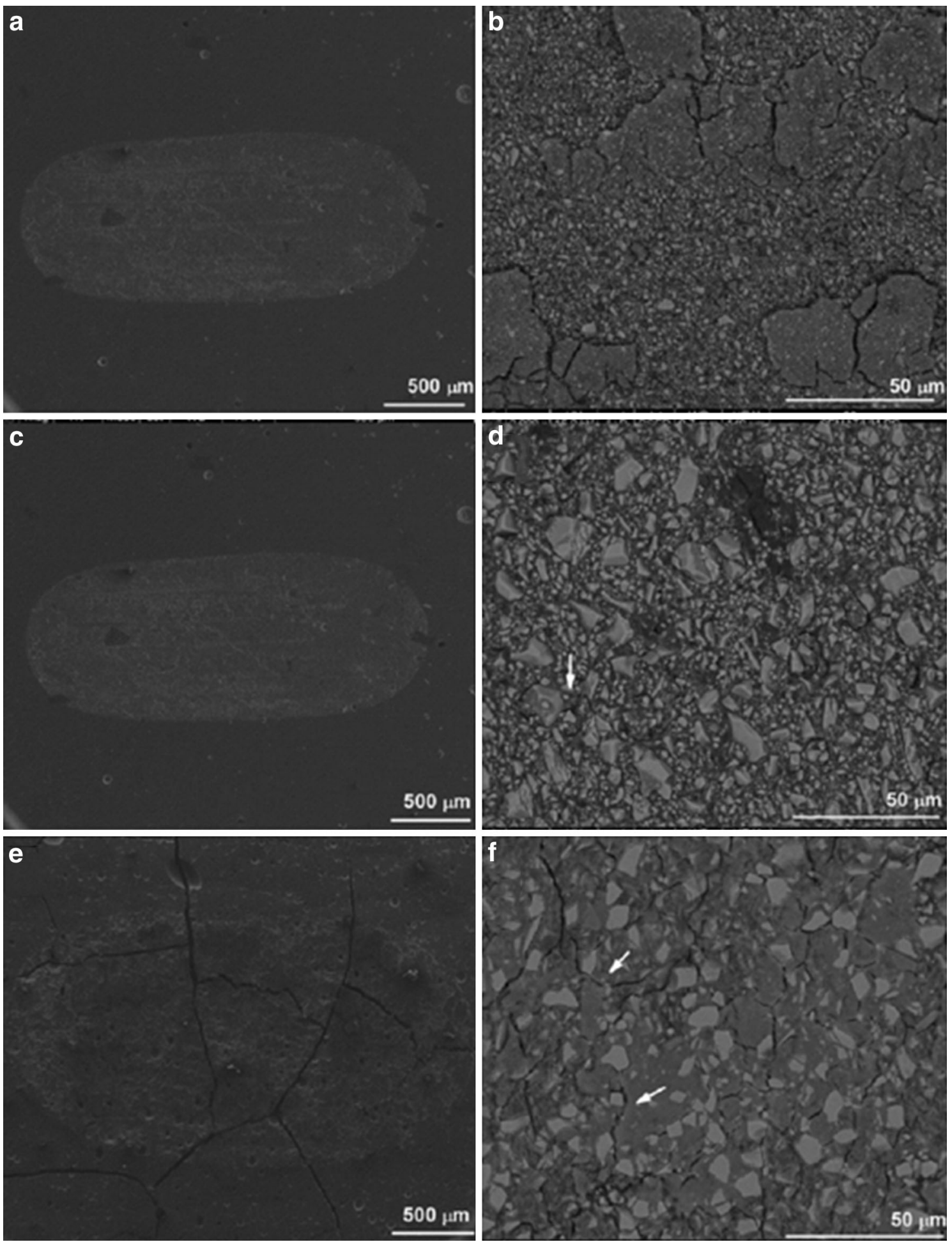

Fig. 5 FEG-SEM images of the worn surface of $(\mathbf{a}, \mathbf{b}) \mathrm{RC}$; (c, d) VI; (e, f) CO. Images a, c, and e represent the wear track. Arrows indicate cracks surrounding the fillers of the worn surface $(\mathbf{d}, \mathbf{f})$

\section{Discussion}

The results of the present study support the rejection of the null hypothesis. They showed that porosity percentage and materials microstructure influenced the materials wear rate, compressive strength as well as the surface roughness.

The results of porosity percentage showed a significant difference among the materials. A lower porosity percentage was obtained in the case of resin composite 


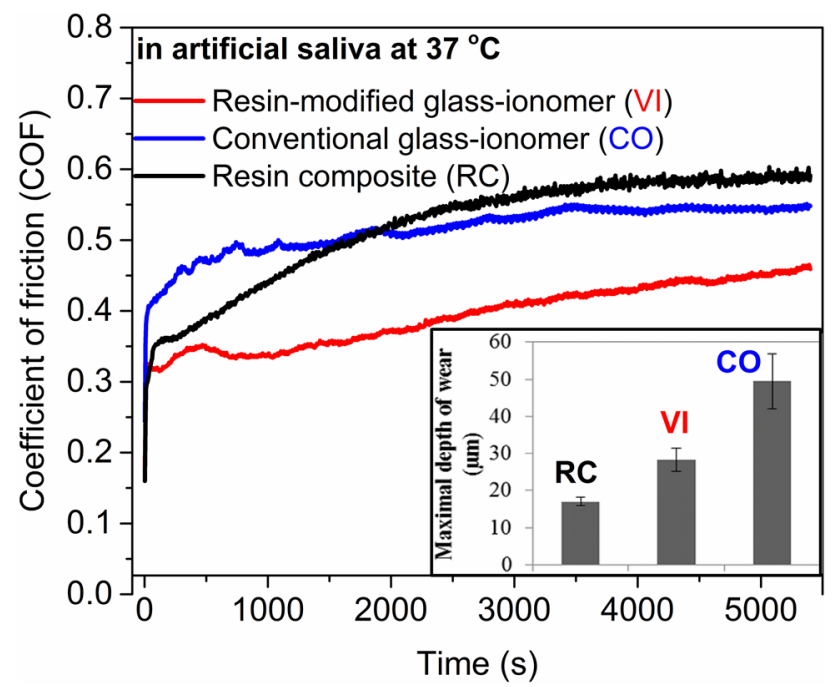

Fig. 6 Mean values of maximum depth recorded on wear track as well as the evolution of the coefficient of friction (COF) recorded on resin composite, resin-modified glass ionomer, and conventional glass ionomer during reciprocating sliding tests at $20 \mathrm{~N}$ performed in artificial saliva at $37^{\circ} \mathrm{C}$ (Color figure online)

compared to that on glass-ionomer and resin-modified glass ionomers as seen in Fig. 1. That corroborates to the findings in previous studies [11-13]. The presence of pores in glass-ionomers microstructure can be attributed to the following factors: air incorporation during powder and liquid hand-mixture that decreases the polymer conversion degree due to inhibition of the setting reaction by the oxygen in the bubbles; placement technique of the material into the tooth cavity where the air bubbles are incorporated or entrapped into the material; and changes in powder/ liquid proportion before mixture [13, 14]. A slower mixing can avoid air incorporation by breaking some bubbles [13, 15]. Considering dental resin composites, the formation of pores can occur during the manufacturing process [12].

Cracks in glass-ionomer-based materials can also occur due to desiccation after chemical reaction [16]. Also, cracks can occur in resin-modified glass ionomer due to the resinous matrix shrinkage during light-curing creating residual stresses between the organic matrix and fillers [17]. On in vitro tests, cracks on glass ionomers can occur during sample preparation for microscopic analyses. That is one of the limitations of in vitro studies. However cracks were not detected in the resin composite microstructure. In fact, fillers treated by silanization promote a chemical bond between fillers and matrix preventing the cracks formation [17].

Pores can act as points of stress concentration and crack propagation leading to failure of the dental restorations. Also, pores can accumulate oral fluids and biofilms affecting color, the degradation of the dental restorations, and gingival inflammation [12, 18-20]. Roughness values recorded on resin composites were lower than that on glass-ionomer-based materials (Fig. 3). The results found in this study are in accordance with previous studies revealing $R_{\mathrm{a}}$ roughness values below $0.2 \mu \mathrm{m}$ [21-23], threshold beyond biofilm accumulation may occur [24]. Therefore, finishing and polishing of the restorations is important to decrease the height of irregularities (peaks and valleys) that provide the accumulation of oral biofilm [23, 25]. Pores and the size of the particles exposed to abrasion contribute to the higher roughness values of the glassionomer restoratives [23]. The high roughness on glass ionomers affects esthetics and mechanical behavior. Roughness peaks concentrate stresses that can promote cracks initiation and consequently facture of the material $[25,26]$. Thus, roughness can be affected by fillers content; fillers hardness; conversion degree of the resin matrix; filler/matrix interaction; and stability of silane coupling agent [21, 25-27]. The addition of nanofillers provides lower roughness values and consequently polishing [21].

In this study, the compressive strength results recorded for resin composites showed values in accordance to other previous studies [28, 29]. However, higher values of compressive strength of glass-ionomer materials are reported in literature [8]. In the present study, the conventional glass ionomers revealed compressive strength values below the threshold value (130 MPa) recommended by ISO 9917 for dental applications [30]. The mechanical properties of the dental materials are influenced by their microstructure. Porosity shows to have a harmful influence on the compressive strength of the material and thus in their clinical performance [11, 13, 15, 31]. Also, the content and molecular weight of polyacids and resins influence the mechanical properties of the glass-ionomer materials. Additionally, the size, content, and distribution of inorganic particles or fillers surrounded by polymeric matrix influence the properties of dental restorative materials [29, 30]. For instance, small size and high content of inorganic particles can improve the mechanical properties of the glass-ionomer or resin composites [8, 32]. Materials containing resinous content such as $R C$ and $V I$ showed better compressive strength values due to the polymeric composition.

The morphological aspects of wear evaluated in the present study revealed differences in degradation on glassionomer and resin composite. The conventional glassionomer material revealed the largest damaged area after reciprocating sliding tests and consequently higher material loss compared to resin-modified glass-ionomer and resin composite. Concerning wear pathways, cracks were noticed at the matrix/glass particles interface in glass ionomers (Fig. 5d, f) that indicated local of stress concentration during reciprocating wear sliding test on glassionomer materials. On resin composites, cracks were 
noticed surrounding a delimited area (rectangle) (Fig. 5b) composed of resinous matrix and fillers. Such wear morphological pathway can take place due to the chemical bonding between polymeric matrix and fillers as well as due to the small size and high proportion of fillers in the resin composite microstructure [33]. Also, the mechanical integrity of matrix/filler interfaces, filler content, and chemical composition influences the friction on surfaces, as seen in Fig. 6. The maximum depth values of wear track (Fig. 6) obtained in the present study are in accordance with a previous study that also revealed a higher vertical wear to the glass ionomer than to the resin composite [34].

In general, the wear pathways are influenced by the following factors: the shape and hardness of the particles; the quality of the bond between particles and matrix; polymerization degree; elastic modulus; mechanical strength; hardness of the counter-body; and environmental conditions that may increase the wear $[35,36]$. The wear of the glass ionomers is influenced by the inherent wear resistance of its constituents, number and size of pores, size and shape of the glass particles, and the integrity of the matrix/glass particle interface [8]. According with Xie et al., the wear of resin composites consists in some possible pathways: (1) resin matrix wear; (2) loss of inorganic particles by failed bonding to resin matrix; (3) loss of material by ejection of inorganic particles; (4) loss of material due to crack propagation and fracture of the matrix.

The present study assessed the porosity percentage, roughness, compressive strength, and wear behavior of dental glass-ionomer and resin composite materials. The compressive strength of the materials was correlated to their chemical composition and microstructure. Therefore, the materials based on resin composite possess higher mechanical strength than that of conventional glass ionomers. In order to mimic oral conditions, this study also performed wear tests of the materials on loading against an alumina counter-body in a Fusayama artificial saliva solution at $37^{\circ} \mathrm{C}$. The electrochemical behavior of such artificial saliva solution has been reported to be similar as in human saliva [36-42]. In fact, it is not possible to simulate all the conditions of the complex oral environment although in vitro studies can validate the influence of each condition on the degradation behavior of biomaterials or biomedical structures as seen in previous studies [36-42]. Further, in vitro studies are required to determine the influence of different parameters on the simultaneous degradation of biomaterials by wear, fatigue, and corrosion in simulated oral enviroments.

\section{Conclusions}

Within the limitations of this study, the following conclusions can be drawn:
- A lower porosity degree was observed in the microstructure of the resin composite than that on glass-ionomer restorative materials. Also, cracks were detected in glass ionomers that can negatively affect their mechanical strength and wear rate.

- In fact, the highest values of compressive strength were obtained for resin composites, followed by resinmodified glass ionomers. Conventional glass ionomers showed the lower values; additionally, higher values of average roughness $\left(R_{\mathrm{a}}\right)$ were reported for conventional glass ionomers, followed by resin-modified glass ionomers.

- Finally, conventional glass ionomers showed the largest wear track area and also the highest maximum wear depth values, followed by resin-modified glass ionomers. FEG-SEM images showed differences in wear patterns between glass-ionomer materials and resin composite, with glass ionomers presenting a uniform pattern unlike the resin composite.

Acknowledgments The authors acknowledge the financial support provided by The Foundation for Science and Technology (EXCL/ EMS-TEC/0460/2012, FCT) and CAPES (Brazilian funding).

\section{Compliance with Ethical Standards}

Conflict of interest On behalf of all the authors, the corresponding author states that there is no conflict of interest.

\section{References}

1. Anusavice KJ (2005) Phillips: materiais dentários. Editora Elsevier, Rio de Janeiro

2. Cramer NB, Stansbury JW, Bowman CN (2011) Recent advances and developments in composite dental restorative materials. J Dent Res 90:402-416

3. Ferracane JL (2011) Resin composite-state of the art. Dent Mater 27:29-38

4. McCabe JF, Walls AWG (2008) Applied dental materials. Blackwell Publishing, Oxford

5. Bonifácio CC, Kleverlaan CJ, Raggio DP, Werner A, de Carvalho RC, van Amerongen WE (2009) Physical-mechanical properties of glass ionomer cements indicated for atraumatic restorative treatment. Aust Dent J 54:233-237

6. Zimehl R, Hannig M (2000) Non metallic restorative materials based on glass ionomer cements-recent trends and developments. Colloids Surf, A 163:55-62

7. Geirsson J, Thompson JY, Bayne SC (2004) Porosity evaluation and pore size distribution of a novel directly placed ceramic restorative material. Dent Mater 20:987-995

8. Xie D, Brantley WA, Culbertson BM, Wang G (2000) Mechanical properties and microstructures of glass-ionomer cements. Dent Mater 16:129-138

9. Smith DC (1998) Development of glass-ionomer cement systems. Biomaterials 19:467-478

10. Sidhu SK (2011) Glass-ionomer cement restorative materials: a sticky subject? Aust Dent J 56:23-30

11. Coldebella CR, Santos-Pinto L, Zuanon AC (2011) Effect of ultrasonic excitation on the porosity of glass ionomer cement: a 
scanning electron microscope evaluation. Microsc Res Tech 74:54-57

12. Elbishari H, Silikas N, Satterthwaite J (2012) Filler size of resincomposites, percentage of voids and fracture toughness: is there a correlation? Dent Mater J 31:523-527

13. Fano L, Fano V, Ma WY, Yang GW, Zhu F (2001) Structure of dental glass-ionomer cements by confocal fluorescence microscopy and stereomicroscopy. Biomaterials 22:2353-2358

14. Fleming GJ, Farooq AA, Barralet JE (2003) Influence of powder/ liquid mixing ratio on the performance of a restorative glassionomer dental cement. Biomaterials 24:4173-4179

15. Nomoto R, Komoriyama M, McCabe JF, Hirano S (2004) Effect of mixing method on the porosity of encapsulated glass ionomer cement. Dent Mater 20:972-978

16. Zoergiebel J, Ilie N (2013) Evaluation of conventional glass ionomer cement with new zinc formulation: effect of coating, aging and storage agents. Clin Oral Invest 17:619-626

17. Feng L, Suh BI, Shortall AC (2010) Formation of gaps at the filler-resin interface induced by polymerization contraction stress gaps at the interface. Dent Mater 26:719-729

18. Da Mata M, Santos-Pinto L, Cilense Zuanon AC (2012) Influences of the insertion method in glass ionomer cement porosity. Microsc Res Tech 75:667-670

19. Mentink AG, Meeuwissen R, Hoppenbrouwers PP, Käyser AF, Mulder J (1995) Porosity in resin composite core restorations: the effect of manipulative techniques. Quintessence Int 26:811-815

20. Miguel A, de la Macorra JC, Nevado S, Gómez J (2001) Porosity of resin cements and resin-modified glass-ionomers. Am J Dent $14: 17-21$

21. Bala O, Arisu HD, Yikilgan I, Arslan S, Gullu A (2012) Evaluation of surface roughness and hardness of different glass ionomer cements. Eur J Dent 6:79-86

22. Da Costa J, Adams-Belusko A, Riley K, Ferracane JL (2010) The effect of various dentifrices on surface roughness and gloss of resin composites. J Dent 38:123-128

23. Gladys S, Van Meerbeek B, Braem M, Lambrechts P, Vanherle G (1997) Comparative physico-mechanical characterization of new hybrid restorative materials with conventional glass-ionomer and resin composite restorative materials. J Dent Res 76:883-894

24. Dos Santos PH, Pavan S, Suzuki TY, Briso AL, Assunção WG, Sinhoreti MA, Correr-Sobrinho L, Consani S (2011) Effect of fluid resins on the surface roughness and topography of resin composite restorations analyzed by atomic force microscope. J Mech Behav Biomed 4:433-439

25. Alandia-Roman CC, Cruvinel DR, Sousa AB, Pires-de-Souza FC, Panzeri H (2013) Effect of cigarette smoke on color stability and surface roughness of dental composites. J Dent 41:73-79

26. Da Silva RC, Zuanon AC (2006) Surface roughness of glass ionomer cements indicated for atraumatic restorative treatment (ART). Braz J Dent 17:106-109
27. Habeeb MA (2013) The surface roughness of new fluoride releasing material after using three polishing protocols and storage in artificial saliva. J Baghdad Coll Dent 25:21-26

28. Jun SK, Kim DA, Goo HJ, Lee HH (2013) Investigation of the correlation between the different mechanical properties of resin composites. Dent Mater 32:48-57

29. Zakir M, Al Kheraif AA, Asif M, Wong FS, Rehman IU (2013) A comparison of the mechanical properties of a modified silorane based dental composite with those of commercially available composite material. Dent Mater 29:53-59

30. Chammas MB, Valarini N, Maciel SM, Poli-Frederico RC, Oltramari-Navarro PVP, Conti ACCF (2009) Resistência à compressão de cimentos de ionômero de vidro restauradores encapsulados. UNOPAR Científica: Ciências Biológicas e da Saúde 11:35-38

31. Fano V, Ortalli I, Pozela K (1995) Porosity in composite resins. Biomaterials 16:1291-1295

32. Xu X, Burgess JO (2003) Compressive strength, fluoride release and recharge of fluoride-releasing materials. Biomaterials 24:2451-2461

33. Drummond JL (2008) Degradation, fatigue and failure of resin dental composite materials. J Dent Res 87:710-719

34. Zhao J, Weng Y, Xie D (2009) A novel high-wear-resistant glassionomer cement for class I and class II restorations. Eur J Oral Sci 117:86-89

35. Heintze SD, Zellweger G, Zappini G (2007) The relationship between physical parameters and wear of dental composites. Wear 263:1138-1146

36. Souza JCM, Henriques M, Teughels W, Ponthiaux P, Celis J-P, Rocha LA (2015) Wear and corrosion interactions on titanium in oral environment: literature review. J Bio-Tribo Corros 1:1-13

37. Souza JCM, Barbosa SL, Ariza E, Celis J-P, Rocha LA (2012) Simultaneous degradation by corrosion and wear of titanium in artificial saliva containing fluorides. Wear 292:82-88

38. Duarte ARC, Silva Neto JP, Souza JCM, Bonachela WC (2012) Detorque evaluation of dental abutment screws after immersion in a fluoridated artificial saliva solution. J Prosthod 22(4):275-281

39. Souza JCM, Ponthiaux P, Henriques M, Oliveira R, Teughels W, Celis J-P, Rocha LA (2013) Corrosion behaviour of titanium in the presence of Streptococcus mutans. J Dent 41:528-534

40. Souza JCM, Henriques M, Oliveira R, Teuhels W, Rocha LA, Celis J-P (2010) Biofilms inducing ultra-low friction on titanium. J Dent Res 89(12):1470-1475

41. Souza JCM, Henriques M, Oliveira R, Teuhels W, Celis J-P, Rocha LA (2010) Do oral biofilms influence the biotribocorrosion behavior of titanium? Biofouling 26(4):471-478

42. Souza JCM, Barbosa SL, Ariza E, Ponthiaux P, Henriques M, Teughels W, Celis J-P, Rocha LA (2015) How do titanium and Ti6Al4V corrode in fluoridated medium as found in the oral cavity? An in vitro study. J Mater Sci Eng C 47:384-393 